\title{
Knowledge and Attitude of a Semi Urban Community in the South-South Region of Nigeria towards Diabetes Mellitus
}

\author{
Faith Osaretin Alele*, Olayinka Stephen Ilesanmi \\ Community Health Department, Federal Medical Centre, Owo, Ondo State, Nigeria \\ *Corresponding author: blazinggold4real@yahoo.com
}

Received November 13, 2013; Revised March 10, 2014; Accepted April 15, 2014

\begin{abstract}
Adequate knowledge of Diabetes Mellitus empowers the community about good health seeking behavior, drug compliance and follow up care. Studies on the knowledge and attitude of the community dwellers are therefore important. This study seeks to access the knowledge and attitude towards Diabetes Mellitus. A descriptive cross sectional study of 384 adults was carried out at Okada in Edo State. Questionnaire was used to collect information and analyzed with SPSS version 15. Descriptive statistics were done and presented as bar charts and tables. Attitude was scored using a Likert scale of 10 questions with maximum attainable mark of 50 points. Respondents with mean score and above were classified as having good attitude. Association between categorical variables were explored using chi square, Level of significance was set at $5 \%$. The mean age of respondents was 34 \pm 11 years, 206 (53.6\%) were males and half of the respondents were married. In all, 243(63.5\%) of the respondents had a good attitude towards diabetes treatment. Lack of health care facilities and attitude of health care providers were the commoner factor preventing respondents from seeking screening for Diabetes. A larger proportion $82.7 \%$ of respondents with tertiary education and $53.2 \%$ of those with primary education had good attitude towards Diabetes treatment. $\mathrm{P}=0.003$. The majority of the respondents have heard about Diabetes but only few of them had a good attitude towards the treatment of the disease. It is therefore important that awareness programs about diabetes should be provided in the community.
\end{abstract}

Keywords: knowledge, attitude, screening, diabetes mellitus, Nigeria

Cite This Article: Faith Osaretin Alele, and Olayinka Stephen Ilesanmi, "Knowledge and Attitude of a Semi Urban Community in the South-South Region of Nigeria towards Diabetes Mellitus.” American Journal of Public Health Research, vol. 2, no. 3 (2014): 81-85. doi: 10.12691/ajphr-2-3-3.

\section{Background}

Diabetes is a chronic disorder that is posing as a great socioeconomic burden to every nation and to the world at large [1]. It is the fourth leading cause of death in most developed countries. Worldwide, over three million deaths are attributable to diabetes - related cases each year. In 2012, the international diabetes federation estimated that more than 371 million people around the world had diabetes. There is a rising prevalence of the disease in subSaharan Africa which has been traditionally dominated by infectious disease, HIV/AIDS, and poverty. This is probably due to rapid urbanization, industrialization, socio economic development and changing life style ${ }^{2}$.The current prevalence of diabetes in Africa is $4.3 \%$ with about 15 million people living with the disease. Nigeria has a prevalence of $4.04 \%$ with about 3 million people living with the disease[2] compared to a previous prevalence of about $2.2 \%$ about a decade ago [3].

Diabetes is now emerging as the new epidemic of the 21st Century and it threatens to swamp the meagre health care resources as well as overwhelm the health care system of many countries in the near future [4]. Being aware of various aspects of the disease is the first step for primary and secondary prevention which is needed at the national and population level [5].

The weapon in the fight against diabetes mellitus is knowledge. With the aid of information people can assess their risk of diabetes as well as seek proper treatment and care and motivate them to take charge of their disease. As it is well known, knowledge empowers individuals about their health conditions as well as educates them about good health seeking behavior [6].

To achieve behavioral change proper counseling and education is required with the involvement of other variables such as diagnosis time, health and disease-related beliefs, family support and easy access to health services. Studies that investigate these variables' relation with DM patients' knowledge and attitudes are still scarce [7]. Early and prompt detection of the disease as well as good drug compliance will aid to achieve good glycemic control [8]. It is perceived that poor knowledge and negative attitude towards diabetes is one of the factors interfering with treatment adherence and metabolic control [9].

Diabetes mellitus needs to be treated by a holistic approach through dietary adjustment, exercise, medication 
(if needed), and education as well as self-care measures. It is a preventable disease therefore it is possible to achieve primary prevention and this involves changing the focus from the individual with diabetes mellitus and management to prevent deterioration of health (secondary prevention), to population-based community-intervention programs. These need to focus on health promoting activities to raise awareness among healthy people of the risk factors for diabetes mellitus $[10,11]$.

Most of the studies done on the knowledge and attitude of community members towards diabetes were carried out in urban communities. Therefore this study seeks to access the knowledge of diabetes among the residents of a semi urban community in the south-south region of Nigeria and their attitude towards the disease.

\section{Methods}

The study was carried out in Okada, a semi urban community in Edo State, Nigeria. Okada is the headquarters of Ovia North East Local Government Area of Edo State. The local government area has a population of 153,849 awith an area of 2,301 $\mathrm{km}^{2}$ at the 2006 census. The predominant occupations of the residents are farming, trading and lumbering [12]. The community has a primary school, a secondary school, a private university (Igbinedion University), churches, a police station, the NYSC orientation camp, a customary court, a town hall and four banks namely: Equitorial Trust Bank, Zenith Bank, Intercontinental Bank and ABC microfinance bank; a primary health center and a teaching hospital, Igbinedion Teaching Hospital.

This is a descriptive cross sectional study. Teenagers and adult residents who have resided in the area for at least one year were included in the study population. Students of Igbinedion University and non-residents of the community were excluded from the study. Sample size was calculated using appropriate formulae. A minimum sample size of 384 was arrived at. Simple random sampling technique was used to select study participants who are willing to participate after seeking informed consent.

Data was collected through Close ended interviewer administered questionnaire. Information collected from the respondents were entered and analyzed with SPSS version 15. Descriptive statistics were done, reported and presented as bar charts and tables using Microsoft Excel and Microsoft Word respectively. Attitude was scored using a Likert scale of 10 questions with maximum attainable mark of 50 points. Respondents with mean score of 25.85 and above were classified as having good attitude towards Diabetes Mellitus. Association between categorical variables were explored using chi square, Level of significance was set at $5 \%$.

We got permission from the Medical Officer of Health of the Local Government Authority as well as the community heads. Informed consent was also obtained from the respondents before administering the questionnaire.

\section{Results}

Table 1 summarizes the socio demographic characteristics of the participants. The mean age of respondents was $34 \pm 11$ years. Of the 384 respondents, 206 (53.6\%) were males and half of the respondents were married and had education up to secondary school level while two thirds of them were artisans and traders.

Table 1. Socio demographic characteristics

\begin{tabular}{|c|c|c|}
\hline VARIABLES & FREQUENCY & PERCENT \\
\hline \multicolumn{3}{|l|}{ AGE } \\
\hline $10-19$ & 43 & 11.2 \\
\hline $20-29$ & 180 & 46.9 \\
\hline 30-39 & 95 & 24.7 \\
\hline 40 and Above & 66 & 17.2 \\
\hline \multicolumn{3}{|l|}{ SEX } \\
\hline Male & 206 & 53.6 \\
\hline Female & 178 & 46.4 \\
\hline \multicolumn{3}{|l|}{ MARITAL STATUS } \\
\hline Single & 153 & 39.8 \\
\hline Married & 219 & 57.0 \\
\hline Others & 12 & 3.1 \\
\hline \multicolumn{3}{|l|}{ LEVEL OF EDUCATION } \\
\hline Primary \& No formal Education & 87 & 22.7 \\
\hline Secondary Education & 241 & 62.8 \\
\hline Tertiary & 56 & 14.6 \\
\hline \multicolumn{3}{|l|}{ OCCPATION } \\
\hline Artisan & 150 & 39.1 \\
\hline Trader & 115 & 29.9 \\
\hline Student & 59 & 15.4 \\
\hline Farmer & 39 & 10.2 \\
\hline Others & 21 & 5.5 \\
\hline
\end{tabular}

Majority of the respondents 353 (92\%) had heard of diabetes while $31(8 \%)$ had not. In all, 243(63.5\%) of respondents had a good attitude towards diabetes treatment while about 141(36.5\%) had a poor attitude towards the treatment of the disease.

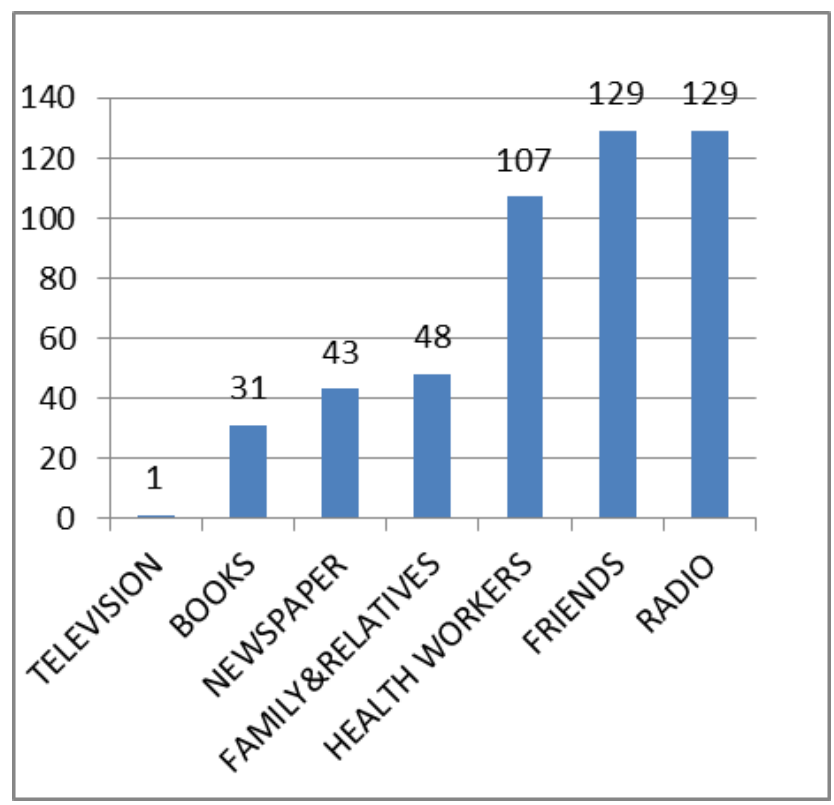

Figure 1. Source of information

Figure 1 shows the various sources of information concerning diabetes among the respondents. Majority of the respondents had obtained information about diabetes from friends (33.6\%) and the radio (33.6\%) while $27.9 \%$ 
heard about the disease from health workers with television (0.3\%) as the least source of information.

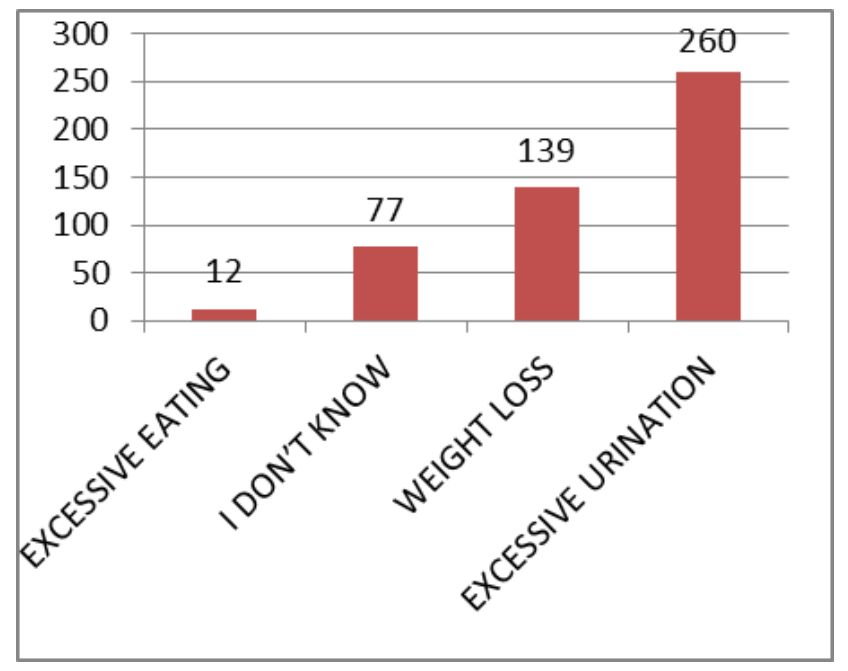

Figure 2. Knowledge of symptoms of diabetes

Figure 2 shows that only $67.7 \%$ of the respondents identified excessive urination as a symptom of diabetes while $36.2 \%$ chose weight loss with poor responses to the options of excessive eating (3.1\%) and $20.1 \%$ had no knowledge about the symptoms of diabetes. Polydipsia (excessive thirst) had $0 \%$ hence it does not reflect in the chart.

Table 2. COMPARISON OF ATTITUDE RATINGS BASED ON THE DEMOGRAPHIC CHARACTERISTICS

\begin{tabular}{|c|c|c|c|c|}
\hline \multirow[t]{2}{*}{ Characteristics } & \multicolumn{2}{|l|}{$\underline{\text { Attitude }}$} & \multirow[t]{2}{*}{$\begin{array}{l}\text { Test } \\
\text { Statistic }\end{array}$} & \multirow[t]{2}{*}{$P$ value } \\
\hline & Poor & Good & & \\
\hline \multicolumn{5}{|l|}{ AGE } \\
\hline $10-19$ & $16(38.1 \%)$ & 26(61.9\%) & & \\
\hline $20-29$ & 64(40.3\%) & 95(59.7\%) & 4.081 & 0.253 \\
\hline 30-39 & $24(27.6 \%)$ & 63(72.4\%) & & \\
\hline 40 and Above & 23(38.3\%) & $37(61.7 \%)$ & & \\
\hline \multicolumn{5}{|l|}{ SEX } \\
\hline Male & 69(37.9\%) & 113(62.1\%) & 0.331 & 0.565 \\
\hline Female & $58(34.9 \%)$ & 108(65.1\%) & & \\
\hline \multicolumn{5}{|l|}{ MARITAL } \\
\hline \multicolumn{5}{|l|}{ STATUS } \\
\hline Single & $51(35.7 \%)$ & 92(64.3\%) & & \\
\hline Married & 72(37.1\%) & 122(62.9\%) & 0.075 & 0.963 \\
\hline Others & $4(36.4 \%)$ & 7(63.6\%) & & \\
\hline \multicolumn{5}{|l|}{ ETHNICITY } \\
\hline Bini & $50(40.3 \%)$ & 74(59.7\%) & & \\
\hline Yoruba & $23(37.7 \%)$ & $38(62.3 \%)$ & & \\
\hline Igbo & $10(31.3 \%)$ & $22(68.8 \%)$ & & \\
\hline Others & $44(33.6 \%)$ & 87(66.4\%) & & \\
\hline \multicolumn{5}{|l|}{ RELIGION } \\
\hline Christianity & 111(35.2\%) & $204(64.8 \%)$ & 2.262 & 0.133 \\
\hline Others & $16(48.5 \%)$ & 17(51.5\%) & & \\
\hline \multicolumn{5}{|l|}{ EDUCATION } \\
\hline Primary & $37(46.8 \%)$ & $42(53.2 \%)$ & & \\
\hline Secondary & 81(37.3\%) & $136(62.7 \%)$ & 11.90 & 0.003 \\
\hline Tertiary & $9(17.3 \%)$ & 43(82.7\%) & & \\
\hline \multicolumn{5}{|c|}{ OCCUPATION } \\
\hline Artisan & $48(35.8 \%)$ & $86(64.2 \%)$ & & \\
\hline Trader & $37(35.9 \%)$ & 66(64.1\%) & 4.201 & 0.379 \\
\hline Student & $18(31.6 \%)$ & 39(68.4\%) & & \\
\hline Farmer & $18(51.4 \%)$ & $17(48.6 \%)$ & & \\
\hline Others & 6(31.6\%) & 13(68.4\%) & & \\
\hline
\end{tabular}

Table 2 shows that $43(82.7 \%)$ of respondents with tertiary level of education had good attitude towards diabetes management compared to $42(53.2 \%)$ those who had primary level of education $(\mathrm{P}=0.003)$. There was no significant relationship between attitude and other socio demographic variables.

Table 3. FACTORS AFFECTING RESPONDENTS' FROM SEEKING SCREENING SERVICES FOR DIABETES

\begin{tabular}{ll}
\hline Factors & Frequency(n) \\
\hline Availability of Health Care Facilities & $280(72.9)$ \\
Accessibility of Health Care Services & $269(70.1)$ \\
Attitude of Health Care Providers & $280(72.9)$ \\
Ignorance & $165(43)$ \\
Culture & $117(30.5)$ \\
Traditional Practices & $214(55.7)$ \\
\hline
\end{tabular}

Table 3 shows the various factors which affect the willingness of the members of the community to access screening services in the health Centre. Availability of health care facilities as well as the accessibility of the health care services alongside the attitude of health care providers is thought to be the major factors while ignorance, culture and traditional practices are among the least regarded factors.

\section{Discussion}

The study of the knowledge of diabetes in various populations has become quite paramount in this scientific and advancing age as part of the measure to control the disease. However knowledge of the disease is not sufficient to battle the menace, it presumes changes in behavior, habits and attitudes [13]. Education is an important aspect of this process and through multidisciplinary approach and community oriented interventions knowledge gap in concerning diabetes will be bridged thereby facilitating an increase in the use of screening services in the undiagnosed and adherence to treatment in those living with the disease. However, the education should be constant because there is a tendency for knowledge to decline over time $[14,15,16]$. This study explored the knowledge and the attitude of the people residing in a semi urban community in south-south part of Nigeria.

In this studied population a large percentage of the respondents had heard about diabetes and most of their source of information was through friends and radio. However they had poor knowledge of the symptoms of diabetes, most of the respondents agreed that excessive passage of urine is a symptom of diabetes which is as a result of osmotic diuresis which occurs with hyperglycemia. Only a few respondents identified weight loss as a symptom while polydipsia was not identified as a symptom of diabetes. This shows that there is a gap in the knowledge about diabetes in the community despite the level of awareness and this can be bridged by a collaborating effort by both the health care system and the community through educational intervention programs.

A study carried out among multi ethnic group community in Glasgow showed that subjects had less knowledge about diabetes, regarded the disease less seriously but with education they showed significant 
improvement in knowledge and attitude towards the disease [17]. In contrast to our studied population, a study conducted among nursing students in the Niger Delta region of Nigeria, showed that the respondents had a poor knowledge of the symptoms of diabetes though the awareness level was relatively high [18].

In another study conducted in Uyo, Akwa Ibom state, Nigeria among adolescents, 120 respondents identified excessive passage of urine as a symptom of diabetes. However other symptoms were less readily identified by the respondents [19]. While in Jordan amongst students at Al-Balqa' Applied University in Al-Zarqa University College, $79.2 \%$ of the students agreed that polyuria is a symptom of DM with few responses to other symptoms [20].

There are other studies which have been conducted among diabetic patients which have also shown that even patients living with the disease had poor knowledge about it. An example is that of a study that was carried out in United Arab Emirates among diabetic patients which show that the levels of knowledge seemed particularly low among the respondents though the general awareness of diabetes symptoms and complications was relatively high [21].

In relation to attitude our respondents performed better, most of them had a good attitude towards the disease. The study revealed that there is a significant relationship with higher level of education and good attitude. This is likely to be due to the fact that a great proportion of the respondents had tertiary education. This coincides with some other studies that have shown that higher school education has a positive effect on diabetic knowledge $[22,23]$. In contrast to this a study that was conducted in University of Benin Teaching Hospital, Benin City, showed that higher education had no significant effect on diabetic knowledge and attitude [24].

Factors such as availability of health care facilities, accessibility of health care services and attitude of health care providers are considered to be responsible for respondents' attitudes towards screening services in the community. Population based approaches governed by the community can identify and reduce the negative factors while supporting the positive factors within the culture alongside environmental changes which have far reaching influences and support adaptive responses among the people [25].

\section{Conclusion}

Diabetes mellitus is gradually becoming a global menace and requires urgent intervention. The study was done to assess the knowledge and attitude of the studied population towards diabetes mellitus and it was discovered that the studied population had a poor knowledge about diabetes as well as poor attitude towards the disease though higher level of education had a significant impact on their knowledge and attitude towards the disease It is therefore important that regular health education programs about diabetes should be provided for the community. Affordable screening centres which members of the community can easily access should also be provided.

\section{Statement of Competing Interest}

The authors have no competing interests.

\section{References}

[1] Ogedengbe OS. Synopsis of diabetes. African journal of postgraduate medicine. Dec 2009; 11(1):102-107.

[2] International diabetes Federation Fifth Edition. www.idf.org accessed October 112013.

[3] Diabetic guideline.blogspot.com. The prevalence of diabetes mellitus in Nigeria updates and challenges. Accessed August 12 2013.

[4] Alberti George. Non-communicable diseases: tomorrow's pandemics. Bulletin of the World Health Organization. 2001;79(10): 907.

[5] Vankudre AJ, Padhyegurjar MS, Gladius H J, SB Padhyegurjar. A study to assess awareness regarding Diabetes Mellitus and factors affecting it, in a tertiary care hospital in Kancheepurum District. Healthline Journal July-December 2013; 4(2): 44-49.

[6] Moodley LM, Rambritch V. An assessment of the level of knowledge about diabetes mellitus among diabetes patients in a primary health care setting. South African Family practice 2007; 49(10): 2078-6204.

[7] Rodrigues FFL, Santos MA, Teixeira CRS, Gonela JT, Zanetti ML Relationship between knowledge, attitude, education and duration of disease in individuals with diabetes. Acta Paulista de Enfermagem 2012; 25(2): 284-90.

[8] Royal pharmaceutical society of Great Britain. The self-care challenge: A Strategy for pharmacists in England (march 2006) available at http:// www.rpsgb.org/pdfs/selfcarechallenge accessed August 252013.

[9] Murata GH, Shah JH, Adam KD, Wendel CS, Bokhari SU, Solvas PA, Hoffman RM, Duckworth WC. Factors affecting diabetes knowledge in Type 2 diabetic veterans. Diabetologia (2003) 46:1170-1178.

[10] Tuomilehto J et al, Prevention of Type 2 Diabetes Mellitus by Changes in Lifestyle among Subjects with Impaired Glucose Tolerance. New England Journal of Medicine 2001; 344: 13431350.

[11] Hjelm K, Mufunda E, Nambozi G, Kemp J. Preparing nurses to face the pandemic of diabetes mellitus: a literature review. Journal of Advanced Nursing 2003; 41(5): 424-34.

[12] 2006 Population and Housing Census of the Federal Republic of Nigeria, www.population.gov.ng accessed October 112013.

[13] Norris SL, Engelgau MM, Narayan KMV. Effectiveness of selfmanagement training in type 2 Diabetes. A systematic review of randomized control trials. Diabetes care 2001; 24: 561-87.

[14] Polikandrioti M. The role of education in diabetes mellitus type 2 management. Health Science Journal, 2010; 4(4): 201-202.

[15] Tessier DM, Lassmann-Vague VJ. Diabetes and education in the elderly. Diabetes and Metabolism Journal, April 2007; 33 Suppl 1: S75-8.

[16] Hansen LJ, Drivsholm TB. Interventions to improve the management of diabetes mellitus in primary health care and outpatient community settings. Ugeskrift for laeger Journal,Jan 2002 28; 164(5): 607-9.

[17] Baradaran HR, Knill-Jones RP, Wallia S and Rodgers A. A controlled trial of the effectiveness of a diabetes education programme in a multi-ethnic community in Glasgow. BMC Public Health Journal, 2006, 6(134): 1471-2458.

[18] Unadike BC. Awareness and knowledge about diabetes mellitus among nursing students in the Niger Delta region of Nigeria. Middle East Journal of Nursing, February 2010, Vol 4 Issue 1: 1834-8742.

[19] Unadike BC, Chineye S. Knowledge, awareness and impact of diabetes among adolescents in Uyo, Nigeria. Diabetes international journal, May 2009: 12-14.

[20] Al-Sarayra L and Khalidi R S. Awareness and Knowledge about Diabetes Mellitus among Students at Al-Balqa' Applied University. Pakistan Journal of Nutrition 11 (11): 1023-1028, 2012.

[21] Al-Maskari F, El-Sadig M,. Al-Kaabi JM , Afandi B, Nagelkerke $\mathrm{N}$, Yeatts KB. Knowledge, Attitude and Practices of Diabetic Patients in the United Arab Emirates, PLoS ONE Journal 2013;8(1): e52857. 
[22] Dickerson FB, Goldberg RW, Brown CH, Kreyenbuhl JA, Wohlheiter K, Fang L, Medoff D, Dixon LB. Diabetes Knowledge among persons with serious mental illness and type 2 diabetes. Psychosomatics 2005; 46: 418-424.

[23] West JD, Goldberg KL. Diabetes self-care knowledge among outpatients at a Veterans Affairs Medical Centre. Am J HealthSystem Pharm 2002; 59: 849-852.
[24] Odili VU, Isiboge PD and Eregie A. Patients' Knowledge of Diabetes Mellitus in a Nigerian City. Tropical Journal of Pharmaceutical Research October 2011; 10 (5): 637-642.

[25] Satterfield DW et al, Community-Based Lifestyle Interventions to Prevent Type 2 Diabetes. Diabetes Care Journal, September 2003; 26(9) 2643-2652. 